radiations have two sharply defined components-a hard component consisting of mesons possessing great energy and a soft component including positrons and electrons. It is known that the soft component, at any rate at sea-level, is genetically connected with the hard component, being appurently generated by the latter. At great altitudes the presence of an unbalanced component has been discovered, namely, radiation that is not directly connected with the hard component. The study of cosmic radiations at great heights is therefore of great importance for the understanding of cosmic radiations as a whole. The question of secondary mesotrons and other strongly ionized agents causing ionization impulses is of great interest. The problem of the generation of secondary mesotrons has gained in significance in recent times.

In order to study mesons, the expedition will make use of an improved form of 'proportional telescope'. In studying cosmic rays at great heights, they will take into consideration 'atmospheric rain', a phenomenon of cosmic rays discovered by a French physicist, P. Auget. Skobeltsyn has studied all the available experimental data, especially those obtained in the Elbrus Laboratory, and has come to the conclusion that a considerable proportion of the impulses are due to processes other than 'Auget's rain'. The expedition will try to prove this by the method of coincidences. An important part of the wirk of the expedition will be the study of the transition effects of the soft component, that is, the processes which occur when rapid protons and electrons leave matter with one atomic weight and enter the orbit of substances with a different atomic weight. The cycle of studies devoted to these particular effects, which was begun before the War, will be continued, employing greatly improved methods which the Atomic Nucleus Laboratory has recently evolved.

\section{Educational Needs in Liberated Countries}

THE sixteenth meeting of the Conference of Allied Ministers of Education was held on March 7 under the chairmanship of the Right Hon. R. A. Butler. The Belgian Minister of Education, M. Buisseret, made a special visit to London in order to attend. Mr. Butler stated that considerable progress has been made towards the establishment of a United Nations organization for educational and cultural reconstruction, and it was announced that it would be possible, after the San Francisco meetings, to make proposals for the final constitution of the new organization. M. Buisseret presented a statement to the Conference stressing the difficult position which has resulted from the Nazis' forceful educational propaganda among teachers and in schools, especially in the small, mainly German-speaking areas of Belgium, which in the course of the occupation had been annexed to Germany. It was pointed out that similar problems might arise in other countries which had suffered occupation. The Conference was informed that a new Commission has been formed "to collect information from liberated countries and elsewhere about the educational needs of, and the work being done for, children and young people requiring special educational treatment; to make the necessary contacts with other bodies engaged on similar activities and to make recommendations to the Conference as to how the information can best be made available and assistance given if desired to the Allied Governments". Mr. J. A. Lauwerys has been appointed to direct the inquiry, and will have his headquarters at 3-5 Salisbury Square, London, E.C.4. The Con- ference adopted the following resolution, and decided that it should be communicated to the Allied Governments through their delegations: "The Conference of Allied Ministers of Education, having considered reports from liberated territory, record their unanimous view that the need for the supply of raw material for educational purposes, and in particular for school books, is of paramount importance. Unless such supplies are made available the Conference believes that the resumption of educational activities will be greatly delayed and additional hardship for the children, students and parents in liberated territories will result."

\section{Restoration of Libraries}

UNDER the auspices of the Conference of Allied Ministers of Education, a committee has been set up to administer the organization and premises known as the Inter-Allied Book Centre, 3-5 Salisbury Square, London, E.C.4, where books can be received and systematically arranged for ultimate allocation to libraries in Great Britain and abroad which have been damaged or destroyed during the War. Already more than a million books, ranging over the whole field of knowledge, have been set aside, by action of the Government, from collections made primarily for selvage purposes. The collection includes books of every kind; but the proportion of modern technical, scientific, commercial and legal works is low. Many libraries will urgently need sets of the more important periodicals, particularly the back numbers of journals and transactions. Those unable to give books or periodicals can support the general scheme by money contributions, which will be used entirely for the purchase of books and periodicals; but so many books have been destroyed, or are in short supply, that the need is for books rather than money. It is generally thought that the committee of allocation should have a free hand to decide the ultimate destination of all books received; but if a donor urgently desires to give to a particular country, or even a particular library, he is asked to com. municate with the director of the Book Centre. Bodies which are already collecting books for specific countries or institutions are asked to supply the director with lists of books and periodicals which they propose to distribute, so that they can be taken into account by the Centre in making its own distribution. Donors are asked to send to the director of the Centre, Mr. B. M. Headicar, lists of the books available; carriage will be refunded, if desired, on all books presented.

\section{Royal Institute of Chemistry}

Ax the sixty-seventh annual general meeting of the Royal Institute of Chemistry held on March 12, at the Institute, 30 Russell Square, W.C.1, Prof. Alexander Findlay, the president, in moving the adoption of the annual report, emphasized the growing opportunities for men of science to bring about a better balance between science and politics and between knowledge and power. The tasks of Government and the formation of a national and international policy which will secure the fullest and most complete development and expression of human nature, when beauty and goodness merge and blend together with truth, depend in part on values other than the scientific, and involve problems which cannot be solved merely by the application of the laws of natural science. But in securing the material wellbeing of the people and in advancing industrial pros- 
perity, science is all-important and, in Prof. Findlay's opinion, representatives of scientific institutions on the Parliamentary and Scientific Committee are playing a particularly important part in keeping the Government informed regarding the discoveries and applications of science to human and industrial wellbeing, and in providing a scientific method of approach to the problems of national administration, a method infused with the spirit of truth rather than of prejudice or party partisanship.

Prof. Findlay stated that the roll of membership of the Institute has increased by 523 to 9,227 , and the register of students by 205 to 1,225 during the past year. He also referred to the greater collaboration among the various organizations of chemists and the better co-ordination of their activitios, in which representatives of the Institute have continued to play their part. He congratulated the Chemical Council on having gained from industrial firms and private subscribers greatly increased financial support for ehemical publications. During the sixty yoars since the Institute was incorporated by royal charter, its membership has increased twenty-fold and there has also taken place remarkable expansion of the activities of chemists. The time has now come to reformulate its aims and interests and to adapt its organization so as the more effectively to achieve its aims and fulfil its responsibilities; proposals for modifying the charter and by-laws are to be laid before the members in due course. Reference was made to the retirement of Mr. Richard B. Pilcher, who had been secretary for fifty years and for forty-five years registrar and secretary, and the appointment of Dr. H. J. T. Ellingham as secretary and Mr. R. L. Collett as registrar. Prof. Findlay was re-elected president.

\section{Pedigree of Fossil Man}

Prof. Ruggles Gates has produced a very concise and interesting article on the pedigree of fossil man (Amer. .J. Phys. Anthrop., 2, No. 3 ; Sept. 1944). $\mathrm{He}$ reviews the opinions of others, discusses modern tendencies and viewpoints, and summarizes his own conclusions. So long as the data supplied relative to the finds of prehistoric man are reliable, the conclusions arrived at by the physical anthropologists must, of course, be treated with great respect. But unfortunately, really well-authenticated and documented discoveries of prehistoric skeletons are more than rare. For example, Prof. Ruggles Gates says : "The evidence of the Committee which investigated the Swarscombe parietal and occipital shows that stratigraphically it is one of the best authenticated of all human remains, and geologically the evidence of the age of the gravels in which they were found is very complete". In the sense that the exact horizon whence came the bones is known, this is certainly true; but it is not enough, for in those Swanscombe gravels both Acheulean and Clactonian industries occur mingled. To say the least, it is still possible that the prehistoric folk who made the coup-de-poing industries were entirely distinct from those flaketool makers who produced the Clacton, Levallois and other flake industries. A study of distribution maps strongly suggests that such a distinction should be made. Now the early flake-tool folk were the ancestors of the Mousterians, that is, of Neanderthal man, whereas the coup-de-poing makers appear'to have quite another story-perhaps an African oneand it is thus still impossible to be certain to which of these two cultural facies the Swanscombe bones belonged. It is not until problems like this- purely matters for the prehistorian to settle-are resolved that the physical anthropologist can satisfactorily do his job. Bearing in mind this warning note, Prof. Ruggles Gates's paper makes interesting and informative reading. He is trying to give answers to just those questions many would like to have elucidated; among other interesting conclusions he places Neanderthal man, in accordance with Weidenreich, in the chain of development from Pitheranthropus and Sinanthropus to "the modern type of man". Not all anthropologists would agree.

\section{Length of Small Intestine}

THE capacity of the human body to withstand remarkable injury or loss of what may seem to be essential organs is continually astonishing those who have to deal with injuries sustained in war and peace or with the results of surgical operations. C. C. Holman (Lancet, 597, Nov. 4, 1944) has reported the instance of a woman who, having survived the removal of her uterus and of the breast for cancer ten and six years earlier respectively, had to sustain, at the age of fifty-six, the removal of twenty feet of her small intestine: a lateral anastomosis was performed between the jejunum and the transverse colon. The patient recovered and three months later had gained $2 \mathrm{lb}$. in weight. A year after the operation she weighed rather more than before her operation and was doing the parish work as a clergyman's wife.

In an Annotation on this case, the Lancet says that people have survived, for several years at least, with only $3 \mathrm{ft}$. of combined duodenum and jejunum and no ileum. It has been calculated (H. E. Haymond, Surg. Gynec. Obstet., 61, 693; 1935) that removal of up to one third of the total length of the small intestine could be followed by return to normal function; but that poor results might follow removal of more than half of it, or eleven feet in average people. It is pointed out, however, that the length of bowel removed gives no true indication of the length which remains, because the total length of small intestine varies between $10 \mathrm{ft}$. and $28 \mathrm{ft} .4 \mathrm{in}$., according to J. Bryant (Amer. J. Med. Sci., 167, 499 ; 1924), who measured the small intestine at autopsy in 160 adults. When the gut is alive, it is a great deal shorter, possibly half the length measured at autopsy or less. Another case, reported by J. A. Cosh in the same issue of the Lancet (p. 596), was less fortunate. This was a man aged sixty-seven, from whom all the small intestine was removed except the duodenum and about $3 \mathrm{ft}$. of the jejunum. For about eight months he had fairly good health, but then became ill and died twelve months after the operation.

\section{Announcements}

Prof. Bengt Edifin, of Lund Observatory, Sweden, has been awarded the Gold Medal of the Royal Astronomical Society for the year 1945 for his identification of the origin of the principal lines in the coronal spectrum.

THE Council of the University of Sheffield has appointed Dr. Harry Moore to the chair of glass technology in succession to Prof. W. E. S. Turner, who is to retire at Christmas 1945 ; Dr. H. A. Krebs to the newly created chair of biochemistry; and $\mathrm{Mr}$. A. E. Bender to be research biochemist in the Department of Pathology, to work in association with the Sheffield Radium Centre. 